\author{
Jarosław Poliszczuk" \\ Instytut Filologii Rosyjskiej i Ukraińskiej \\ Uniwersytet imienia Adama Mickiewicza w Poznaniu
}

\title{
Przypadek Zuzanny Ginczanki
}

\section{Streszczenie:}

Przedmiotem obserwacji badawczej pozostaje w artykule postać artystyczna Zuzanny Ginczanki (wł. Zuzanny Poliny Gincburg, 1917-1944). Była to polska poetka pochodzenia żydowskiego. Zadebiutowała w Warszawie w latach 30. XX wieku. W okresie II wojny światowej stała się jedną z ofiar Holocaustu. Legenda Ginczanki skupia uwagę na jej tragicznym losie i wczesnej śmierci w wieku zaledwie 27 lat. Niemniej jednak, twórczość poetycka tej autorki zasługuje na nasze uznanie. Jest ostatnimi laty doceniana przez badaczy. Poliszczuk rozważa w swoim tekście artystyczno-płciowy kryzys tożsamości Ginczanki, wyraźnie obecny w jej twórczości. Językowa i kulturowa orientacja Ginczanki skłaniała ją do wyboru polskości. Doznane przez poetkę prześladowanie na gruncie rasowym, a także potrzeba poznania korzeni kierowały ją w stronę kultury żydowskiej. Natomiast język rodzinny łączył ze światem kultury rosyjskiej, którą traktowała z dystansem. Tak czy inaczej, Zuzanna Ginczanka doznała swego rodzaju stanu „heroicznej zdrady”, zarówno

Jarosław Poliszczuk - prof. dr hab., pracownik Zakładu Ukrainistyki Uniwersytetu imienia Adama Mickiewicza w Poznaniu; ostatnio opublikował książki Reaktywność literatury (Реактивність літератури, Київ 2016) oraz Topografia hybrydowa. Miejsca i nie-miejsca we wspótczesnej literaturze ukrainskiej (Гібридна топограбія. Місия і немісия в сучасній украӥнській літературі, 2018). yaropk@gmail.com 
wobec swego pochodzenia, jak i języka. Obecnie jej oryginalna postać po raz kolejny intryguje badaczy oraz interpretatorów, a poezję artystki warto dziś odczytywać jako szczególny rodzaj palimpsestu kulturowego.

Słowa-klucze: poezja, biografia, język, tożsamość, ironia, tragizm.

\section{The case of Zuzanna Ginczanka}

\section{Summary:}

The subject of a research observation presented in the article is an original aristocratic profile of Zuzanna Ginczanka (proper name: Zuzanna Polina Gincburg, 1917-1944). She was a Polish, Jewish-origin poet who had her debut in Warsaw in the 1930s. During World War II she became one of the Holocaust victims. The legend of Ginczanka is focused on her tragic fate and early death at the age of 27 . Nonetheless, her poetic work deserves our attention. It has recently been appreciated by researchers. Poliszczuk deliberates on Ginczanka's artistic and sexual identity crisis, so explicitly expressed in her work. Ginczanka's linguistic and cultural orientation inclines her to choose the Polish nationality. Racial persecution suffered by the poet as well as the need to explore her roots directed her towards the Jewish culture. However, the language used in her family linked her with the world of Russian culture, which she treated with distance. Anyway, Zuzanna Ginczanka felt a sort of "heroic betrayal”, both in terms of her origin and language. At present, her original profile again intrigues researchers and commentators, and the artist's poetry is also worth perceiving as a special kind of cultural palimpsest.

Key words: poetry, biography, language, identity, irony, tragedy. 
Ubiegłoroczny stuletni jubileusz Zuzanny Ginczanki, mimo że nie wywarł większego echa w środowiskach intelektualistów polskich, pokazał, jak ważne jest poszukiwanie nowych określeń dla podobnych zjawisk, których istota tkwi w nieustannym dialogu kształtów kulturowych. Przeplatanie w tym przypadku elementów polskich, żydowskich, rosyjskich oraz ukraińskich jest o tyle skomplikowane, że dodatkowo nakłada się na realia epoki totalitaryzmów, w których wybór jednostki nierzadko był z góry przesądzony, a podziały społeczne powodowały utożsamienie jednoznaczne, wykluczające kompromisy wobec pochodzenia, rodzinnego języka, właściwego locum, wyznania itp. Inaczej patrzymy na te rzeczy obecnie, wyraźnie uświadamiając sobie, że żyjemy w świecie otwartych i chwiejnych tożsamości, w którym jednoznaczne identyfikacje są z góry skazane na niewystarczalność i okazjonalność. Według koncepcji transkulturowości wybitnego filozofa Wolfganga Welscha, charakterystyczną cechą naszego czasu jest wzajemne przenikanie rozmaitych czynników, co tworzy żywą tkankę kultury i nadaje jej za każdym razem aktualny kształt. To wzajemne powiązanie różnych elementów, ich wpływanie na siebie sprawia, iż całościowy opis jednego, określonego zjawiska okazuje się ideałem nie do osiągnięcia. Pamięć przeszłości wobec tego nie jest wolna od polifonii oraz relatywizmu kulturowego, zależy bowiem od procesu ciągłej wymiany, dialogu, przeobrażeń, które w każdym momencie historii ją kształtują ${ }^{1}$.

Przypadek Zuzanny Ginczanki w takim kontekście wydaje się być bardzo interesujący. Odsłonięcie szczegółów biografii poetki² a także badanie jej twórczości uświadamia, jak mocno przeplatały się w jej osobowości artystycznej wspomniane wyżej przesłanki kulturowe. Jak twierdzi Izolda Kiec, autorka pierwszej monografii poświęconej twórczości Ginczanki, jej biografia stanowi osobny tekst, dosyć często zbieżny ze szczegółami utwo-

1 W. Welsch, Transkulturowość. Nowa koncepcja kultury, [w:] Filozoficzne konteksty koncepcji rozumu transwersalnego. Wokót koncepcji Wolfganga Welscha, cz. 2, red. R. Kubicki, Poznań 1998, s. 195-223.

2 Z ostatnich publikacji na ten temat warto wymienić artykuł Ryszarda Kotarby oparty na materiałach źródłowych, zob. R. Kotarba, Zuzanna Ginczanka: śmierć poetki. Historia okupacyjna, „Gazeta Wyborcza”, 14 grudnia 2015 roku, http://wyborcza.pl/ alehistoria/1,121681,19333036,zuzanna-ginczanka-smierc-poetki-historia-okupacyjna. html?disableRedirects=true [dostęp: 09.08.2018 r.]. 
rów bądź wyjaśniający okoliczności ich powstania czy rozliczne konteksty, ale nie całkiem tożsamy z twórczością, równoległy wobec niej³. Zresztą, niemniej charakterystyczny także mit Ginczanki, utrwalony w literaturze wspomnieniowej po II wojnie światowej: w swoim czasie bardzo ważny dla przywrócenia jej dzieła, odzwierciedlił jednocześnie stereotypowe ujęcie poetki jako ofiary naznaczonej samym losem.

Ostatnio coraz więcej uwagi przyciąga dzieło Ginczanki pod względem jego wymowności kulturowej, przecież przesłanki wielokulturowości i nawarstwienia różnych wpływów w tym przypadku są inspirujące. Uobecnienie i przeplatanie w tekstach poetki różnych kodów językowych zauważyła w swym czasie Kiec, twierdząc:

Biografia, jak się okazuje, znajduje też swe odzwierciedlenie na poziomie językowego ukształtowania tekstu. Prywatne doświadczenia Ginczanki, związane z dominacją rosyjskiej mowy w jej rodzinnym domu i samodzielną decyzją dotyczącą tworzenia w języku polskim, widoczne są w zakresie rytmiki wiersza oraz słowotwórczej inwencji poetki. Nierzadko tłumaczą też potoczność, a nawet niezręczności stylu najwcześniejszych jej dokonań ${ }^{4}$.

Chęć ponownego odkrywania tej niezwykłej postaci uwidacznia się w opracowaniach młodych badaczy z czasów ostatnich ${ }^{5}$, a to z kolei wskazuje, że wobec Ginczanki mogą być stosowane współczesne podejścia badawcze, zaś interpretacja jej wierszy może stać się intrygującą przygodą dla młodego intelektualisty.

Zuzanna Ginczanka to pseudonim literacki autorki, znanej jako Zuzanna Polina Gincburg (1917-1944). Była postacią wyrazistą i charyzmatyczną. Mimo krótkiego i niełatwego życia pozostawiła po sobie jaśniejące blaskiem wspomnienie. Poetka urodziła się w Kijowie w zasymilowanej rodzinie żydowskiej rozmawiającej w domu po rosyjsku.

3 I. Kiec, Zuzanna Ginczanka. Życie i twórczość, Poznań 1994, s. 166-167.

4 Tamże.

5 Zob. A. Araszkiewicz, „Wypowiadam wam moje życie”. Melancholia Zuzanny Ginczanki, Warszawa 2001 oraz D. Wojda, „Sprawy korzenne”. Fenomenologia Zuzanny Ginczanki, „Przestrzenie Teorii” 2017, nr 28, s. 269-280. 


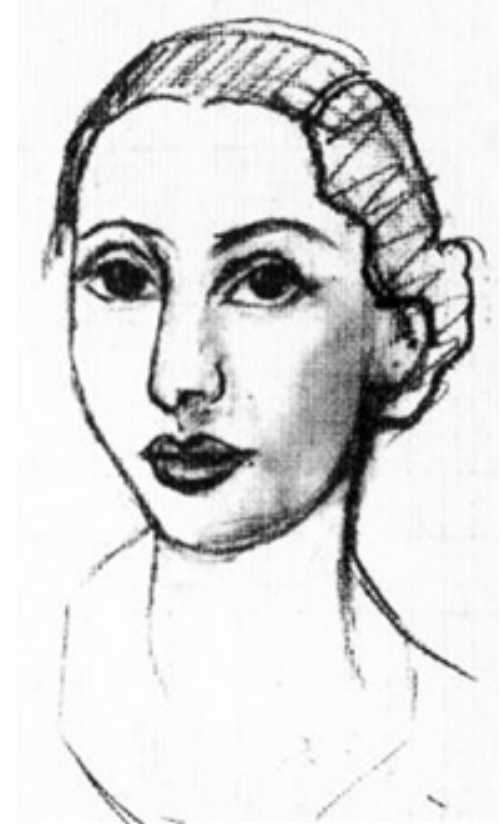

Graficzny portret poetki nieznanego autora.

Jej krewni w czasach zawieruchy rewolucyjnej, uciekając z Kijowa, zatrzymali się w Równem na Wołyniu, a następnie wyemigrowali z kraju. Zuza natomiast zatrzymała się na dłużej w prowincjonalnym wołyńskim miasteczku. Wychowywała ją babcia, prowadząca własny skład apteczny, który pozwalał im na utrzymanie się. Równe zamieszkiwała wówczas dość liczna społeczność żydowska, jedna z najbardziej dobrze zorganizowanych w tej części kraju. Wychowanie Zuzanny było w miarę liberalnym, do niczego jej nie zmuszano, a sama już w młodzieńczym wieku wykazywała silny charakter. Związany jest z tym właśnie świadomy wybór tożsamości kulturowej. W dzieciństwie przecież Zuza słyszała w swoim otoczeniu różne języki, ale wybrała dla siebie polski, w którym rozmawiały jej przyjaciółki (według informacji podanych we wspomnieniach), dzięki czemu znalazła się później w polskim gimnazjum państwowym im. Tadeusza Kościuszki w Równem. Lata spędzone w tej szkole były dla niej bardzo ciekawe i bogate w przeżycia. To właśnie w tym okresie Ginczanka zaczęła pisać wiersze oraz zadebiutowała w prasie. Sukces w lite- 
raturze odniosła w roku 1934, kiedy jej wiersz nieoczekiwanie zwyciężył w konkursie ogłoszonym przez warszawskie czasopismo „Wiadomości Literackie". Ponadto, przeważnie w Równem zostały napisane utwory, które weszły do pierwszej i jedynej książki wydanej jeszcze za jej życia, w 1936 roku w Warszawie.

Pierwsze wiersze Zuzanna napisała w wieku 10 lat. Opublikowała je w szkolnej gazetce samodzielnie redagowanej przez gimnazjalistów („Echa Szkolne”). Od tej pory marzyła, żeby zostać poetką. Sprzyjały temu szkolne znajomości: dobrzy nauczyciele dostrzegający talenty uczniów (zwłaszcza Ewa Szelburg-Zarembina, wówczas znana pisarka) i prawdziwi przyjaciele. Po gimnazjum Sana (tak była nazywana w gronie przyjaciół) postanowiła rozwijać swoje zdolności. Przeprowadziła się więc do Warszawy, gdzie dostała się na Uniwersytet Warszawski. Studiowała pedagogikę na Wydziale Humanistycznym. W tym czasie intensywnie uczestniczyła w życiu towarzyskim, często bywała w kawiarniach literacko-artystycznych, gdzie zawierała znajomości z wieloma pisarzami, którzy byli (lub później nimi się stali) najwybitniejszymi gwiazdami polskiej literatury. Ginczanka spędzała czas w towarzystwie m.in. Witolda Gombrowicza, Andrzeja Nowickiego, Józefa Łobodowskiego etc.

Przyjaźniła się również z przedstawicielami grupy poetyckiej „Skamander", ale w zasadzie miała szerokie koło znajomych, w tym także na Wołyniu, skąd pochodziła i dokąd chętnie wracała w okresy świąteczne i wakacyjne. Jednakże jej oszałamiający sukces w środowisku artystycznym, co wielokrotnie zostało odnotowane we wspomnieniach, chyba zbyt jednostronnie i płasko charakteryzuje postać Ginczanki. Za maską uśmiechniętej i przyjaznej dziewczyny ukrywała się też inna tożsamość, którą poetka umiejętnie chowała przed światem. Obdarzona talentem artystycznym zdawała sobie sprawę z ciemnej strony otaczającej ją rzeczywistości, znała cenę cierpienia i dobrze odczuwała tragizm bytu. To dobrze daje się dostrzec $\mathrm{w}$ jej wierszach, w których przejawia się istota sprzeczna i kontrowersyjna, bogata w różnorodne obrazy, eksponująca kobiecą tożsamość jako duch inności, występując jednocześnie w różnych odmianach - jako „gwałtowna, czarująca straszliwa”6.

\footnotetext{
6 M. Janion, Kobiety i duch inności, wyd. 2, Warszawa 2006, s. 31.
} 
Debiutancki tomik poezji O centaurach (1936) sprawił, że nazwisko Ginczanki stało się znane w gronie elity literackiej stolicy Rzeczypospolitej. Ale jej pierwsza książka nie daje całościowego wrażenia o talencie pisarki. Należy bowiem brać pod uwagę liczne utwory publikowane w periodykach i dopiero niedawno zebrane w krytyczny zbiór, opracowany przez Kiec ${ }^{7}$.

Wiersze Zuzanny Ginczanki cechowało swoiste połączenie melancholii i ironii, przez które uwidaczniała się niepewność stanowiska młodej poetki. Owo niezdecydowanie można zaobserwować w kilku odcieniach. Agata Araszkiewicz zauważa efekt jej wyobcowania przynajmniej w dwóch kontekstach: „Ginczanka jako pisząca kobieta i jako Żydówka była podwójnie obca $\mathrm{w}$ tradycji literackiej polskiej [...]. Podobnie pierwszy raz można tu mówić o tworzącej się odrębnej kobiecej subkulturze literackiej"8.

Poetka współpracowała z czasopismami, publikując nie tylko wiersze, ale również satyry. Przygotowywała audycje radiowe. Jednak atmosfera zbliżającej się wojny dawała o sobie znać. Przejawiała się ona między innymi w antysemickiej kampanii z drugiej połowy lat 30 . XX wieku ${ }^{9}$, która dotknęła bezpośrednio także Ginczankę. Nastroje niepokoju, zagrożenia, desperacji w wierszach Zuzanny Ginczanki mają swoje uzasadnienie, mimo że mogą być interpretowane na rożne sposoby. Wydaje się jednak, że decydujący wpływ na samoidentyfikację tej autorki miały wahania tożsamościowe, związane z poszukiwaniem własnego miejsca w procesie kulturowym, z nieokreśloną wizją własnego ,ja” artystycznego i kobiecego.

Tego typu niepewność była w latach 30/40. XX wieku podsycana przez sameokolicznościżyciaitwórczościpoetki:próbykarieryartystycznej,ostrzeżeniazestrony nieżyczliwej krytyki, a takżeciągłezagrożenieiprześladowanie w latach 1939-1944. Wybór polskiej tożsamości nie uchronił Ginczankę od ostrych zarzutów dotyczących jej pochodzenia żydowskiego. Warto przytoczyć opinię jednego z krytyków, który oskarżał ją (podobnie jak innych polskich pisarzy pochodzących z rodzin żydowskich), odmawiając przynależności do kultury polskiej. Krytyk (Tadeusz Dworak) wyrażał

7 Z. Ginczanka Wiersze zebrane, oprac. I. Kiec, Warszawa 2014.

8 A. Araszkiewicz, dz. cyt., s. 8.

$9 \dot{Z} y d z i$ w literaturze. Materiały XII konferencji pracowników naukowych i studentów, red. A. Szawerna-Dyrszka, M. Tramer, Katowice 2003, s. 97-99. 


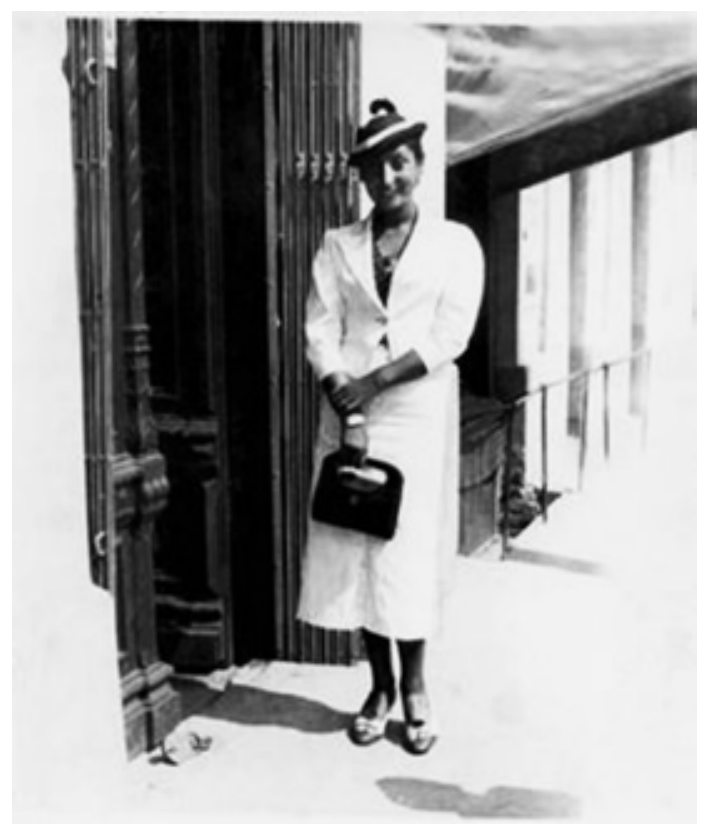

Zuzanna Ginczanka w swoim rodzinnym Równem (1938).

w istocie rozpowszechnione wówczas ujęcie tożsamości „czystej” i destylowanej, twierdząc: „Wiersze Żydów w języku polskim nie należą do rdzennej, czystej poezji polskiej. Nie należą także do rdzennej żydowskiej literatury narodowej”, zatem wnioskował, że są one „produktem asymilacji drugorzędnych cech kultury polskiej"10.

Stąd pochodzą wewnętrze rozterki poetki, jej poczucie zagubienia i tragicznego losu, którymi są naznaczone wiersze końca lat 30. XX stulecia. Akceptacja polskiego języka i polskiej kultury nie mogła zostać w jej przypadku absolutna - z powodów obiektywnych i subiektywnych - $\mathrm{i}$ nastręczała napięcia $\mathrm{w}$ relacjach $\mathrm{z}$ różnymi środowiskami. Pisanie w języku wyuczonym to zawsze trudny wybór dla literata, dla którego język jest czymś większym, niż tylko sposobem wypowiadania własnych sądów i, można by rzec, stanowi wartość sakralną. Odczuwanie niepewności i okaleczeń w języku dostarcza przeżyć traumatycznych dla takiej jednost-

10 Zob. P. Łopuszański, Warszawa literacka $w$ okresie międzywojennym, Warszawa 2017, s. 386. 
ki. Wystarczy przytoczyć zdanie Emile’a Ciorana, który doskonale wyraził poczucie wyobcowania, prześladujące go przez całe życie z powodu podobnych rozterek na gruncie językowo-kulturowym: „Kto porzuca swój język dla innego, zmienia swoją osobowość. Dokonuje heroicznej zdrady, zrywając ze swoją przeszłością i do pewnego stopnia z samym sobą"11.

Ginczanka, jak się wydaje, miała kłopoty z określeniem tożsamościowym w potrójnym sensie. Jako Żydówka zasymilowana posiadała nikłą wiedzę o rodzimej kulturze, nie znała języka swoich przodków. Jednakże, w miarę nasilenia ucisków na gruncie rasowym musiała dostrzegać swoją tożsamość żydowską wyraźnie, jak to się stało z wieloma jej rodakami. Zresztą lata jej przechowywania w okresie wojny dostarczały wiele ciężkich refleksji na ten temat. W jedynym zachowanym wierszu z owej doby oświadczała ze zjadliwą ironią:

Pamiętam o was, wyście, kiedy szli szupowcy,

Też pamiętali o mnie. Przypomnieli i mnie.

Niech przyjaciele moi siądą przy pucharze

I zapiją mój pogrzeb i własne bogactwo:

Kilimy i makaty, półmiski, lichtarze

Niechaj piją noc całą, a o świcie brzasku

Niech zaczną szukać cennych kamieni i złota

W kanapach, materacach, kołdrach i dywanach.

0 , jak się będzie palić w ręku im robota..."12

W kulturze polskiej tak samo nie była ona zakorzeniona, mimo że język opanowała doskonale i chętnie angażowała się w sprawy polskie w gronie swoich przyjaciół Polaków. Trudne, naznaczone traumą wewnętrzną, wyrosłą z dzieciństwa poetki, były też jej relacje z kultura rosyjską. W okresie 1939-1941 znajomość rosyjskiego miała się przydać pisarce w sowietyzowanym Lwowie, gdzie uzyskała ona status quo członkini Związku Pisarzy ZSRR. Jednakże, w zasadzie nie skłoniło to

11 E. Cioran, Dogodności i niedogodności wygnania, przeł. W. Gombrowicz, „Kultura" 1952, nr 6, s. 3.

12 Z. Ginczanka, Wiersze zebrane, dz. cyt., s. 393. 
Ginczanki do przejścia w sferę wpływów kultury rosyjskiej (w jej edycji sowieckiej). Ograniczyła się natomiast do kilku tłumaczeń z rosyjskiego, jakich dokonała, prawdopodobnie broniąc w ten sposób swojego prawa do życia i samorealizacji twórczej ${ }^{13}$. Zatem dokonanie „heroicznej zdrady" w przypadku Ginczanki nie przyniosło jej większej satysfakcji, nastręczając jednakże rozterek wewnętrznych, którym w swoim czasie i właściwych okolicznościach poetka nie była w stanie sprostać ${ }^{14}$.

Zuzanna Ginczanka była osobą towarzyską, otwartą i pełną życia. Te kilka fotografii, które przechowuje Muzeum Literatury w Warszawie, ma dziś znaczenie symboliczne. Na jednym ze zdjęć Ginczanka stoi na progu rówieńskiego domu, inne przedstawia ją na którejś z ulic miasta, pozostałe - podczas wypoczynku z przyjaciółmi nad jeziorem Basów Kąt czy w sosnowym lesie pod Klewaniem. Jest na nich przeważnie zainspirowana, śmiała, uśmiechnięta, w miłym towarzystwie. Przybiera efektowne pozy do zdjęć.

O wyjątkowej osobowości i wiernej przyjaźni poetki świadczą nie tylko wspomnienia jej najbliższych osób. Wystarczy popatrzeć na zachowane grupowe zdjęcia, na których Sana niezmiennie znajduje się w centrum uwagi, wesoła i zawzięta. Co prawda, jej wesołość wcale nie znaczyła, że była beztroska czy lekkomyślna. W poezji Zuzanny ciągle przeplatają się dwa krańcowo różne motywy - optymizm i fatalizm, przejmująca ra-

13 O trudnych warunkach pisarzy w ówczesnym Lwowie i kompromisach z władzą sowiecką patrz: M. Inglot, Polska kultura literacka Lwowa lat 1939-1941. Ze Lwowa i o Lwowie. Lata sowieckiej okupacji w poezji polskiej. Antologia utworów poetyckich w wyborze, Wrocław 1995; М. Ільницький, Драма без катарсису. Сторінки літературного життя Львова першої половини ХХ століття, Львів 1999 oraz Ch. Mick, Lwów pod sowieckim panowaniem, 1939-1941, [w:] Stalin i Europa. 1928-1953, oprac. T. Snyder, R. Brandon, przeł. S. Kędzierski, Poznań 2014, s. 131-149. Doskonale wyeksponował sytuację terroru i totalnego lęku we Lwowie również Aleksander Wat we wspomnieniach z tego okresu: A. Wat, Mój wiek. Pamiętnik mówiony, cz. 1, rozmowy prowadził i przedmową opatrzył Cz. Miłosz, Warszawa 1990, s. 256-308.

14 W podobny sposób kryzys tożsamości był przeżywany przez twórców na emigracji - Miłosza, Gombrowicza, Herlinga-Grudzińskiego etc., jak twierdzi badacz problemu: M. Stępień, Wśród emigrantów, Kraków 2007, s. 53-54. Z tą różnicą, że emigranci odczuwali Ojczyznę jako wartość utraconą dla siebie wskutek opuszczenia kraju. Ginczanka przez cały czas raczej przebywała na emigracji wewnętrznej, uświadamiając sobie ciągłe istnienie granic językowo-kulturowych, które ją w różnym stopniu krępowały bądź dręczyły. 
dość życia i mistyczne przeczucie śmierci. Jej życiorys nie bez powodów jest uważany za niezwykle cenne świadectwo epoki. Podobne wrażenie odnosimy też na temat jej twórczości, która z ogromną przenikliwością przedstawia wewnętrzny świat młodej osoby w dobie europejskiej katastrofy pierwszej połowy XX wieku.

Od momentu, gdy Niemcy w czerwcu 1941 roku okupowali Lwów, Zuzanna przechowywała się dzięki pomocy przyjaciół. Mieszkała nielegalnie najpierw we Lwowie, a następnie w Krakowie. Donosu i aresztowania nie udało się jednak uniknąć. Jeszcze jesienią 1943 roku nielegalnie mieszkała pod Krakowem. Została rozstrzelana przez Niemców akurat przed przyjściem Armii Czerwonej. Jej bezimienny grób znajduje się na przedmieściach, gdzie zostały pochowane liczne żydowskie ofiary nazistów.

O tragicznym losie Zuzanny dowiedziano się już po II wojnie światowej. Pamięci Ginczanki dedykowano nostalgiczne wiersze i wspomnienia. W ten oto sposób ocaleni przyjaciele - Jan Śpiewak, Józef Łobodowski, Anna Kamieńska, Julian Przyboś etc. - pragnęli przywrócić współczesnym jej jaskrawą i niezapomnianą postać sprzed wojny. Kazimierz Brandys wspominał: „To jedno z moich świętych widm, które mnie nawiedzają. Żydowska uroda i śpiewna poezja, oczy sarny, żydowskie ucieczki i kryjówki, dla mnie są w tym ponadczasowe symbole, jak w opowieściach biblijnych" ${ }^{15}$. Jeszcze bardziej przenikliwy obraz autorki Centaurów zachował w swej pamięci Józef Łobodowski. To właśnie on poświęcił jej tom wierszy Pamięci Sulamity, wydany w Kanadzie w 1987 roku. Wspominał o Ginczance jako o legendzie życia kulturalnego przedwojennej polskiej stolicy i ówczesnej literatury.

W XXI wieku osobliwa postać Zuzanny Ginczanki po raz kolejny intryguje i przyciaga. Jest ona dobitnym przykładem funkcjonowania kultury na zasadzie palimpsestu, kiedy stare teksty wywołują nowe, czasem zupełnie niespodziewane skojarzenia, a otwartość kulturowa sprzyja niezaangażowanemu odczytaniu tego, co wydawało się wiedzą niedostrzeżoną, utajnioną, tabuizowaną. 
Jarosław Poliszczuk, Przypadek Zuzanny Ginczanki

\section{Bibliografia}

Araszkiewicz Agata, „Wypowiadam wam moje życie”. Melancholia Zuzanny Ginczanki, Warszawa 2001.

Cioran Emil, Dogodności i niedogodności wygnania, przeł. Witold Gombrowicz, „Kultura" 1952, nr 6.

Foto: http://culture.pl/pl/tworca/zuzanna-ginczanka.

Ginczanka Zuzanna, Wiersze zebrane, oprac. Izolda Kiec, Warszawa 2014.

Ilnickijj Mikola, Drama bez katarsisu. Storinki literaturnogo zhittja Lvova pershoï polovini XX stolittja, Lviv 1999.

Inglot Mieczysław, Polska kultura literacka Lwowa lat 1939-1941. Ze Lwowa i o Lwowie. Lata sowieckiej okupacji w poezji polskiej. Antologia utworów poetyckich w wyborze, Wrocław 1995.

Janion Maria, Kobiety i duch inności, wyd. 2, Warszawa 2006.

Kiec Izolda, Zuzanna Ginczanka. Życie i twórczość, Poznań 1994.

Kotarba Ryszard, Zuzanna Ginczanka: śmierć poetki. Historia okupacyjna, "Gazeta Wyborcza", 14 grudnia 2015 roku, http://wyborcza.pl/alehistoria /1,121681,19333036,zuzanna-ginczanka-smierc-poetki-historia-okupacyjna. html?disableRedirects=true [dostęp: 09.08.2018 r.].

Łopuszański Piotr, Warszawa literacka w okresie międzywojennym, Warszawa 2017.

Mick Christoph, Lwów pod sowieckim panowaniem, 1939-1941, [w:] Stalin i Europa. 1928-1953, oprac. Timothy Snyder, Ray Brandon, przeł. Sławomir Kędzierski, Poznań 2014, s. 131-149.

Stępień Marian, Wśród emigrantów, Kraków 2007.

Wat Aleksander, Mój wiek. Pamiętnik mówiony, cz.1, rozmowy prowadził i przedmową opatrzył Czesław Miłosz, Warszawa 1990.

Welsch Wolfgang, Transkulturowość. Nowa koncepcja kultury, [w:] Filozoficzne konteksty koncepcji rozumu transwersalnego. Wokół koncepcji Wolfganga Welscha, cz. 2, red. Roman Kubicki, Poznań 1998, s. 195-223.

Wojda Dorota, „Sprawy korzenne”. Fenomenologia Zuzanny Ginczanki, „Przestrzenie Teorii" 2017, nr 28, s. 269-280.

Żydzi w literaturze. Materiały XII konferencji pracowników naukowych i studentów, red. Anna Szawerna-Dyrszka, Maciej Tramer, Katowice 2003. 